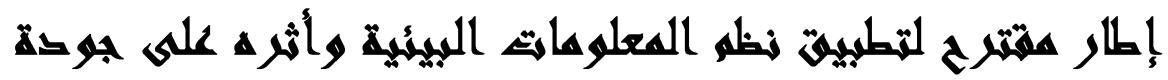

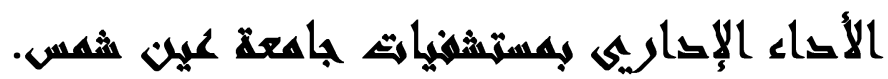 \\ [rr]
}

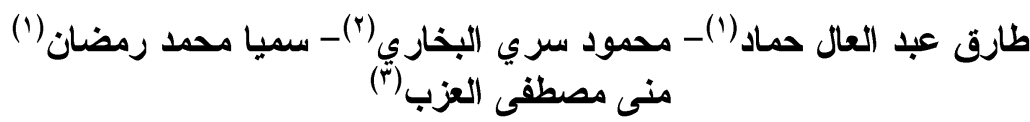

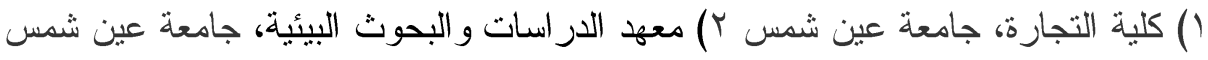
r) كلية الطب، جامعة عين شمس.

\section{المستخلص}

هدفت الدراسة إلى التعرف على الواقع الفعلى لإستخدام نظم المعلومات الصحية

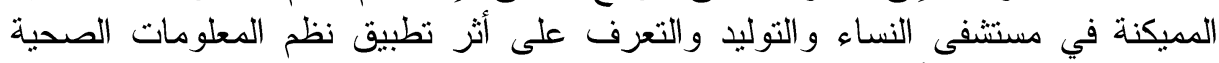

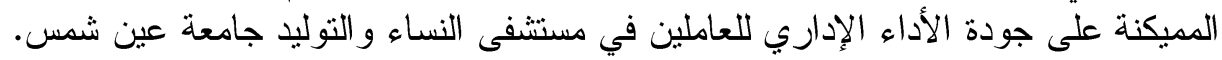

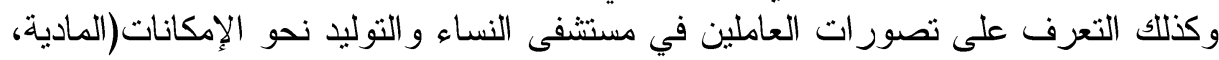

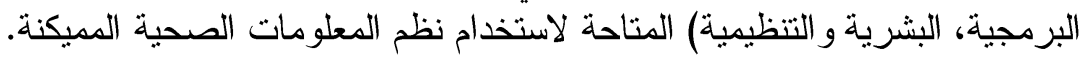

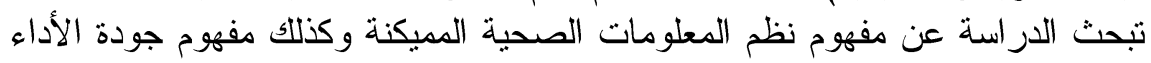
الإداري، و افترضت الدراسة وجود علاقة ارتباط بين تطبيق نظم المعلومات البئية البئية الصحية

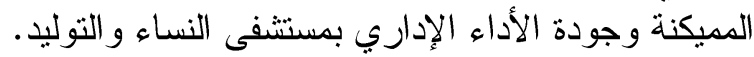

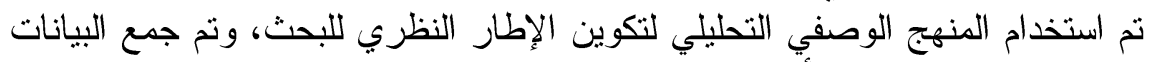

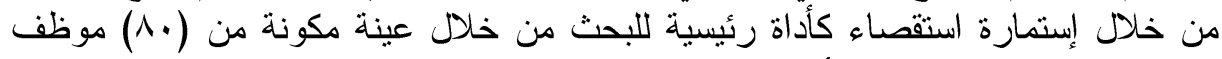

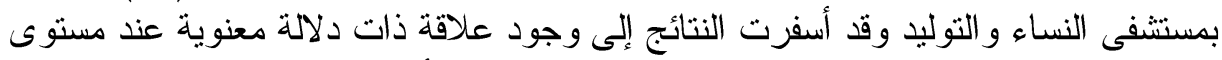

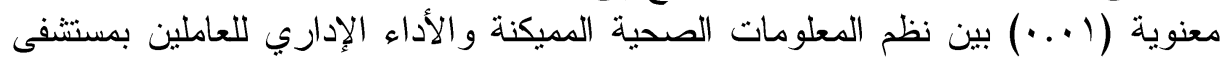
النساء و التوليد.

أوصت الدراسة بإنشاء قسم فني متخصص بنظم المعلومات الصحية المميكنة، عقد الدور ات التدريبية في مجال استخدام نظم المعلومات الصحية، الاهتمام بتوفير شبكات حديثة تمتاز بسرعة الاتصال. 


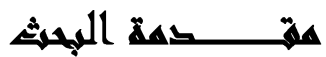

لقد أعطى الله سبحانه وتعالى للبيئة موازينها الدقيقة وقوانينها المُحكمة وأمرنا بإستخدام ثرواتها لتعمير الحياة على الأرض دون إفساد أو إسراف، ولقد إهتمت دراسات عديدة بتحديد العوامل المؤثرة على نجاح نظم المعلومات أهمها تدعيم الإدارة العلىا لجهود تطبيق النظم، ومشاركة المستخدم في تطوير وتنفيذ النظم، وجودة الإدارة لعملية تنفيذ النظم، ومساهمة المستخدم وتأثير المستخدم، والإتصالات بين المستخدم و المطور، و وإتجاهات المستخدم، والقيود على الموارد التنظيمية ودرجة التعقد (تعقد المهام، تعقد النظم) ودرجة النضج الوظيفي، وحجم المنظمة(إيمان إبر اهيم حسان : V. V. Y).

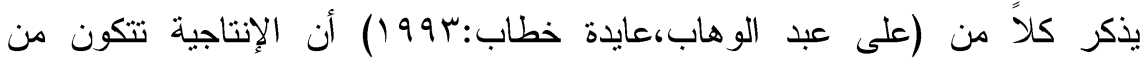

$$
\text { الألتغاء: التكنولوين أساسيين هما الأداء و التكنولوجيا. }
$$

أصبحت الحاجة للتغيير في أساليب العمل الحكومي أكثر إلحاحاً وخاصة مع بداية الألفية الجديدة بسبب التطور المتسارع في التكنولوجيا، و التأكيد المتز ايد على الجودة

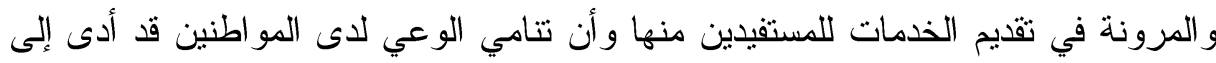

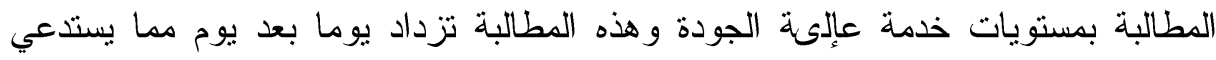
الأمر إلى ضرورة تحسين وتطوير أسلوب تقديم الخدمات وتبسيط إجراءات الأداء وتقديم الخدمات بسر عة لما يترتب على ذلك من توفير بالوقت وجودة بالأداء(حسين أحمد الطرو انه

يعتبر منهج إدارة الجودة الكلية من المناهج الحديثة في الإدارة و التي يمكن أن نتبناه المستثفيات بصفة عامة وبصفة خاصة المستثفيات الجامعية من أجل الوصول إلى أفضل أداء ممكن، ويعتمد تطبيق إدارة الجودة الكلية في المستشفيات الجامعية على مدى التزام

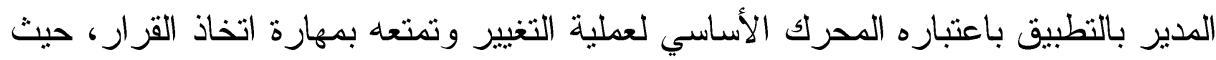


وجود المدير المتحمس لمفهوم إدارة الجودة الكلية من الممكن أن يسهل إلى حد كبير عملية النطبيق و التحسين المستمر .

تواجه مستشفيات القرن الحادي و العشرين العديد من التحديات العالمية و المحلية مما يقلل من القدرة التشغيلية وطاقات توصيل الخدمات الصحية للمرضى فى المجالات الطبية الوقائية والعلاجية المختلفة ولم تصبح المنافسة فى مجالات شركات الأدوية وإدارة المستشفيات ترجع فقط إلى حجم الإستثمارات أو عدد الأطباء و الهيئة التمريضية، ولكن ولنه ولهن

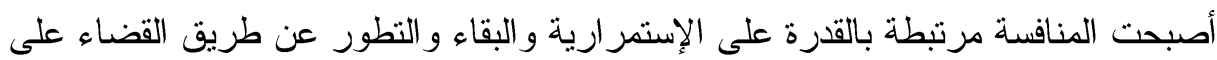
التهديدات الخارجية ونقاط الضعف التنظيمى الداخلى(فريد النجار : V. . Y. ب). عندما تواجه المستشفيات توفر الفرص التشغيلية المختلفة مثال الطلب على الخدمات العلاجية و الوقائية مع نقص الإمكانات الداخلية تلجأ إذن للمشاركات و التحالفات الإستر اتيجية

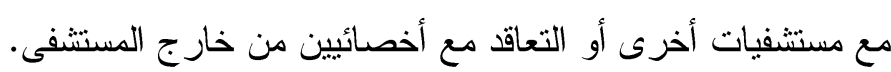

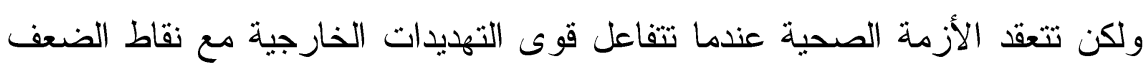
النتظيمى والإدارى مثال نقص الإمكانيات أو غياب المعلومات الصحية أو نقص الطص الطاقة

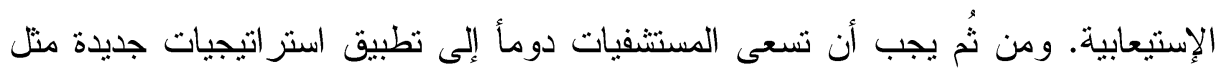
إستخدام نظم معلومات صحية مميكنة للقضاء على الضعف التتظيمى الداخلى ولتخفيض آثار التهديدات الخارجية والوصول إلى جودة الأداء الإداري.

\section{الدراسائ العابية}

أولاً: الار اسة المتعلقة بنظم المعلومات البيئية الصحية المميكنة:

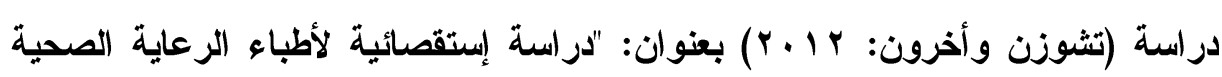
الأولية في عشر دول يظهر التقدم في استخدام تكنولوجيا المعلومات الصحية، وأقل في مناطق أخرى": دراسة مسحية دولية على أطباء الرعاية الصحية الأولية في(· •() بلدان

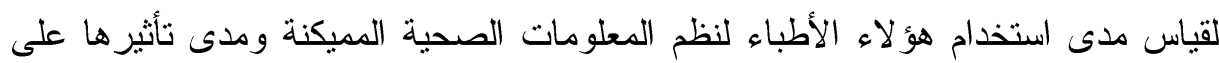


حيث قام الباحثون بإجر اء المسح لأطباء الرعاية الصحية الأولية في(• (1) بلدان هي :

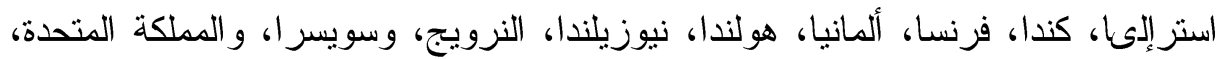

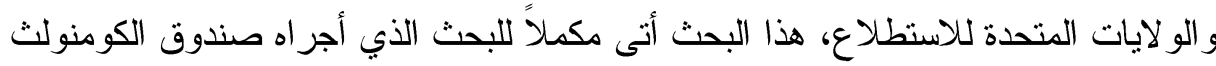

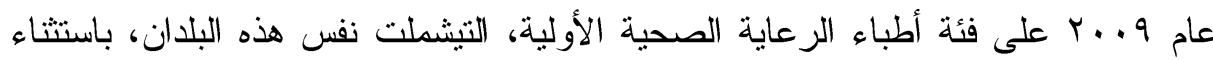

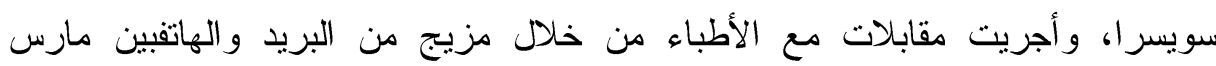

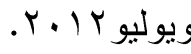

نتائج الاراسة: وجود تقدماً في استخدام تكنولوجيا المعلومات الصحية في ممارسات

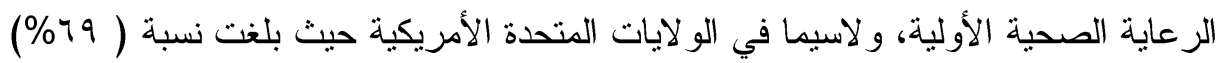

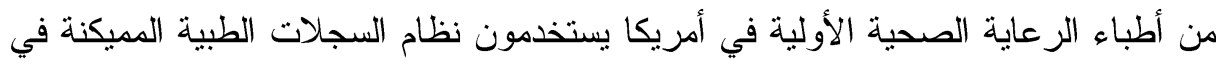

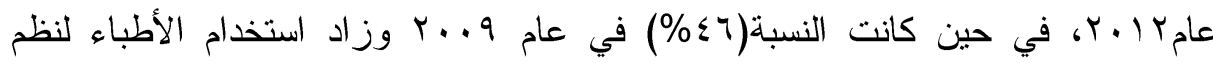
المعلومات الصحية بشكل كبير في كل من أمريكا وكندا بالرغم من تأخر هذين البلدين في مجال السجلات الطبية المميكنة مقارنة ببلدان منل بريطانيا ونيوزيلندا و استر اليا.

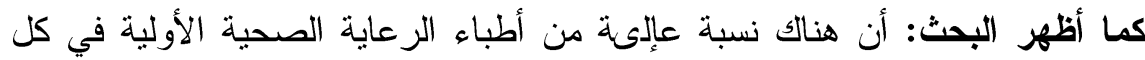

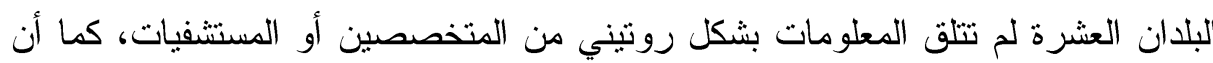
هناك نسبة جيدة في الدول العشرة تدل على تحسن أداء الطبيب، وأظهر المسح أن الغالبية

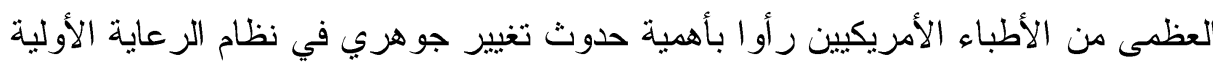
المتبع حاليًا. ثانياً: الار اسة اليا: المتعلقة بالأداء الإداري:

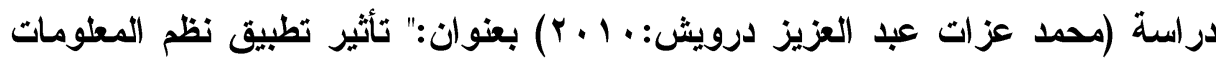

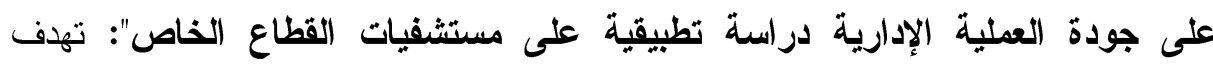
الدراسة إلى التعرف على المشكلات التي تواجه نظم المعلومات في جودة العملية الإدارية وتحديد إتجاهات الجودة في نظم المعلومات. 


\section{نتائج الدر اسةة:}

أ. يوجد تأثير ذات دلالة إحصائية لتطبيق نظم المعلومات على جودة العملية الإدارية.

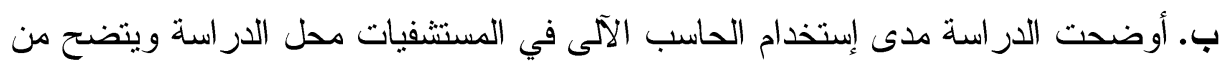
تلالك المؤشرات أن المستشفيات ( مفردة الدراسة ) يستخدمون الحاسب الآلي في أغلب الأنشطة في حين بعض المستشفيات لا يستخدمون الحاسب الآلي ويستخدمونه في

$$
\text { الحالات النادرة. }
$$

ج. ويتضح من الدراسة السابقة أن النسبة الكبيرة من المستشفيات (مفردة الدراسة) تقوم بحفظ وتسجيل البيانات بإستخدام سجلات ورقية إما بالنسبة الأقل تيستخدم تسجيل وحفظ البيانات بإستخدام وسائظ تخزينية حاسوبية.

د. ويتضح من عملية تطبيق نظم المعلومات قدرتها على إستخدام نظم المعلومات في عمل فله إستتناجات في أسباب المشكلات و الوصول إلى تحسين الأداء داخل المستشفى من خلال نظم المعلومات و التفاعل مع المرضى تتطلب مجهود كبير ، يؤدي كل ذلك إلى تحسين الأداء الكلي لتلك المستشفيات وتعظيم الربح وتدعيم الوضع التنافسي.

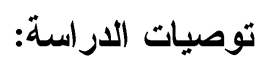
أ. تطبيق الأساليب العلمية عند الإعتماد على نظم المعلومات الإدارية مما تساعد على تقديم

$$
\text { الاعم الكافي لجودة العملية الإدارية. }
$$

ب. التعرف على متطلبات نظم المعلومات الإدارية والمساعدة على رفع مستوى أداء نظم المعلومات بالمنظمة.

ج. يجب على الجهات والأجهزة الحكومية والهيئات المعنية العمل على تفعيل نظم المعلومات وتيسير خفض تكاليف إنشاء نظم المعلومات لكافة المستشفيات.

د. تدريب وتأهيل العاملين بالتعامل مع نظم المعلومات وأساليب وطرق التعامل معها.

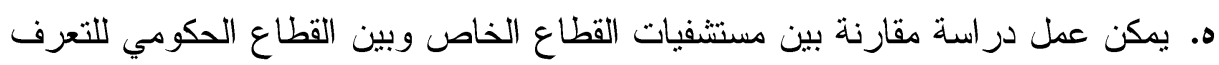
على عو ائد تطبيق نظم المعلومات على الأداء و القدرات التنافسية. 


\section{هشخلة البحثي}

نظراً لأن دراسة نظم المعلومات الصحية المميكنة وأثزها على جودة الأداء الإداري

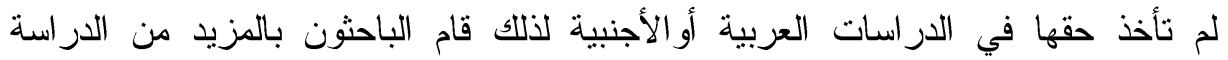
و البحث.

وإن الحاجة إلى نظم المعلومات البيئية الصحية المميكنة في المستشفيات تزداد كلما كان هناك عدداً كبيراً من البيانات و التي يتم معالجتها وتحويلها إلى معلومات تقيد العديد من المستخدمين.

كذلك النطور السريع في المجال الطبي والخدمات الصحية في العقود الأخيرة دعى لزياد الطلب على المعلومات الصحية المناسبة لإتخاذ القرارات الطبية والإدارية، حيث أن مدر اء الصحة وو اضعي السياسات يحتاجون لمعلومات مناسبة ودقيقة لقياس فعالية البر امج لونج ومتابعة تقدمها لتحقيق الأهداف لمنشودة، لذلك فان إستخدام نظم المعلومات الصحية المميكنة كوسيلة لرفع كفاءة الأداء الإداري.

تسعى هذا الدر اسة إلى التعرف على مدى ملائمة المستلزمات الدات الرئيسية لإدارة ونتشغيل

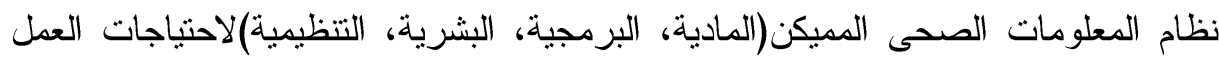
في مستثفى النساء والتوليد من خلال معرفة هذا الأثر نستطيع الوقوف على مواضع الخلل في نظام المعلومات الصحى المميكن فيها وبالتلى محاولة علاجه ومن ثم نتمكن من تطويره

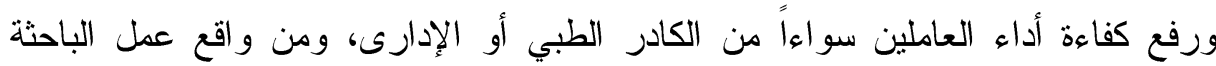
كموظفة إدارية بالمستشفى لاحظت ذلك الخلل فى نظام المعلومات الصحى المميكن داخل المستنثفى. وبالتالى يمكن تحديد مشكلة البحث في هذا السؤال الرئيسي: هل يؤثر تطبيق نظم المعلومات البيئية الصحية المميكنة على جودة الأداء الإداري للعاملين في مستشفى النساء والتوليد؟ 


\section{أسئلةالمبشث}

يتفرع عن هذا التساؤل نساؤلات فرعية هي: 口 هل يؤثر نو افر الإمكاناتالبشرية المتاحة على جودة الأداء الإداري للعاملين في مستشفى النساء و التوليد؟ 口 هل يؤثر نو افر الإمكاناتالمادية المتاحة على جودة الأداء الإداري للعاملين في مستشفى النساء و التوليد؟ 口 هل يؤثر تو افر الإمكاناتالتنظيمية المتاحة على جودة الأداء الإداري للعاملين في مستشفى النساء و التوليد؟ 口 هل يؤثر تو افر الإمكاناتالبرمجية المتاحة على جودة الأداء الإداري للعاملين في مستشفى النساء و التوليد؟

\section{أهمية المبهث}

تبحث بشكل خاص فى تطبيق نظم المعلومات البيئية الصحية المميكنة وأثره على

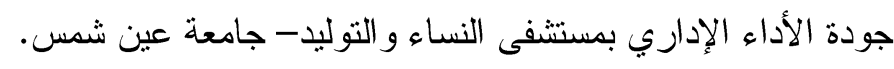

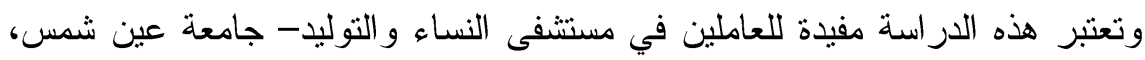

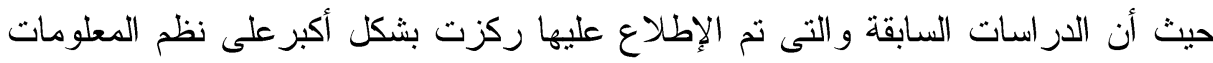
الإدارية والنظم التقنية بشكل عام في حين عانت نظم المعلومات الصحية المحوسبة أو

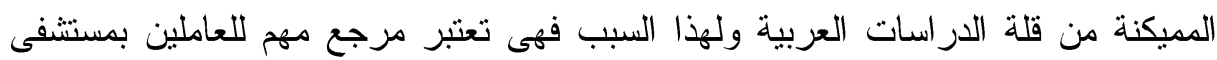
النساء و التوليد.

وكذلك تكمن أهمية الدراسة في أنها تساعد صناع القرار والقائمين على مستشفى النساء و التوليد في التعرف على مو اطن القوة و الضعف بخصوص نظم المعلومات الصحية المميكنة المستخدمة حالياً وعلاقتها بالأداء الإداري لتعمل في رسم السياسات الكفيلة بتطوير هذه النظم مما يترتب علىة الوصول إلى جودة الأداء الإداري للعاملين بها. 


\section{أهقاهي المبحث}

1) دراسة الواقع الفعلى لاستخدام نظم المعلومات الصحية المميكنة في مستشفى النساء و التوليد.

r) دراسة أثر تطبيق نظم المعلومات الصحية المميكنة على جودة الأداء الإداري للعاملين في مستثفى النساء و التوليد. r) دراسة تصورات العاملين في مستثفى النساء والتوليد نحو الإمكانات (المادية، البرمجية، البشرية و التتظيمية)/المتاحة لاستخدام نظم المعلومات الصحية المميكنة.

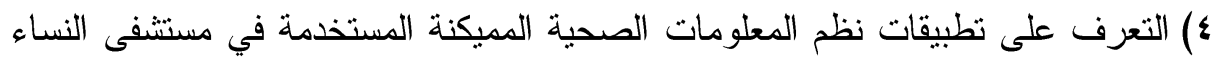
و التوليد في مجالات الأعمال الإدارية و الطبية.

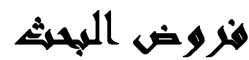

بعد التعرف على أهداف البحث يمكن صياغة فروض البحث على النحو التالى: الفرض الرئيسي: لا توجد علاقة معنوية بين تطبيق نظم المعلومات البيئية الصحية المميكنة وجودة الأداء الإداري بمستثفى النساء و التوليد.

\section{يتفرع من هذا الفرض عدة فروض على النحو التالى:}

口 لا نوجد علاقة معنوية بين نو افر الإمكانات البشرية المتاحة لاستخدام نظم المعلومات الصحية المميكنة وجودة الأداء الإداري.

口 لا توجد علاقة معنوية بين نو افر الإمكانات المادية المتاحة لاستخدام نظم المعلومات الصحية المميكنة وجودة الأداء الإداري. ه لا توجد علاقة معنوية بين تو افر الإمكانات التنظيمية المتاحة لاستخدام نظم المعلومات الصحية المميكنة وجودة الأداء الإداري. ه لا نوجد علاقة معنوية بين توافر الإمكانات البرمجية المتاحةلاستخدام نظم المعلومات الصحية المميكنة وجودة الأداء الإداري. 


\section{متخغير ائ المبحث}

المتغير التابع: جودة الأداء الإداري للعاملين بمستشفى النساء و التوليد.

المتغير المستقل: نظم المعلومات الصحية البيئية المميكنة ويتفرع منه: ( الإمكانات البشرية المتاحة لاستخدام نظم المعلومات الصحية|المميكنة. r) الإمكانات المادية المتاحة لاستخدام نظم المعلومات الصحية المميكنة. r) الإمكانات التنظيمية المتاحة لاستخدام نظم المعلومات الصحية المميكنة. ع) الإمكانات البرمجية المتاحة لاستخدام نظم المعلومات الصحية المميكنة. •) تطبيقات نظم المعلومات الصحية المميكنة المستخدمة. و الثكل رقم (1): يوضح ذلك:

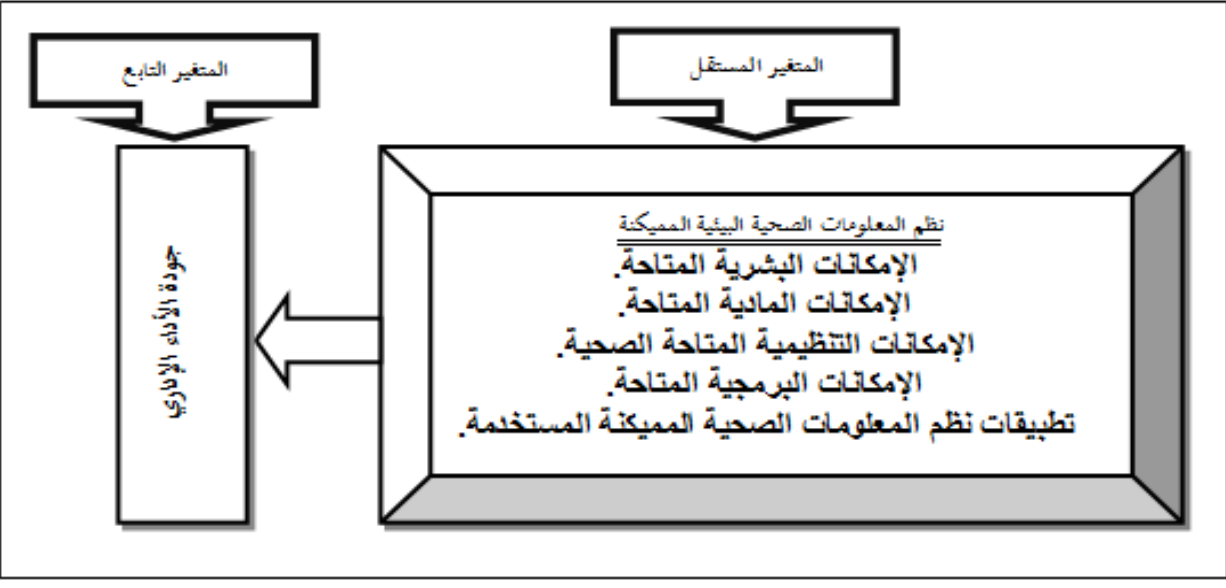

المصدر: الباحثة 


\section{هiهمج المبحثي}

يعتمد هذا البحث على المنهج الوصفى التحليلي للوصول إلى الأهداف المحددة من قبل

الباحثة ويقوم هذا المنهج على الجمع بين الدراسة المكتبية و الدراسة الميدانية:

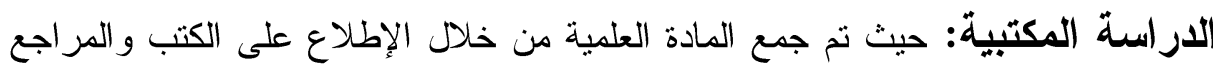
العربية و الأجنبية و الدوريات و المجلات العلمية و الدراسات المتعلقة بموضوع البحث إضافة

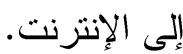
الاراسة الميدانية: يتم التأكد من صحة الفروض من خلال جمع البيانات والمعلومات اللازمة ذات الصلة بموضوع البحث من خلال تصميم قائمة إستقصاء وتوزيعها على عينة البحث و إجر اء المقابلة الثخصية و الملاحظة المباشرة.

\section{حبوك المبهث}

حدود مكانية: داخل أقسام(شئون العاملين- الصيدلية- الحسابات- شئون الأطباء الثطب - عيادة الحوامل - قسم الأشعة التشخيصية).

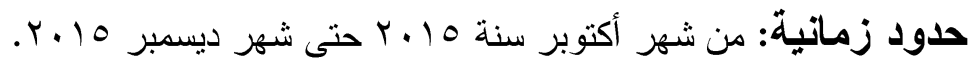

\section{هجتمع واينة المبهثي}

تم اجر اء الدراسة على مستشفى النساء والتوليد بمستشفيات جامعة عين شمس من أقسام شئون العاملين - الصيدلية- الحسابات- شئون الأطباء - الشطب - عيادة الحوامل قسم الأشعة التشخيصية).

\section{هصطالحايت المبهث}

الأداء الإداري: المهام التي يقوم بها الموظف في المنظمة و النتائج الفعلية التي يحققها في

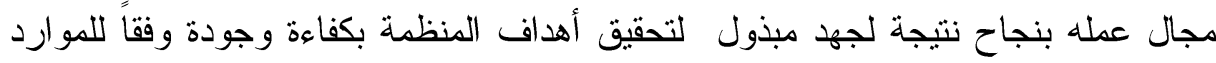
المتاحة و الأنظمة الإدارية و القو اعد و الإجر اءات و الطرق المحددة للعمل. 
جودة الأداء الإداري: تتفيذ الأعمال المطلوبه بشكل صحيح (بإحسان) من أول مرة دون

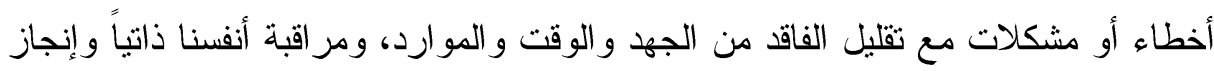
نتائج غير مسبوقة يتفوق بها على نفسه وعلى الأخرين وأن يتحاشى قدر الإمكان التعرض الته للخطأ.

نظم المطلومات الصحية المميكنة: مجموعة من النظم الميكنة الثاملة والمتكاملة التي

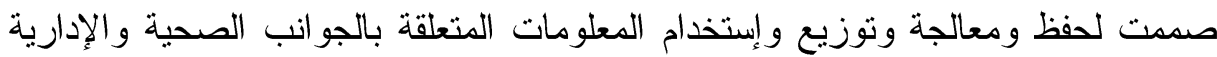
بالمستشفى. البياتات الصحية: مواد المعرفة حول المرضى كل على حدة، أو للجموعات المرضى، والبيانات الخاصة بالمريض موجودة في ورق أو على شكل إلكتروني أثناء زيارته

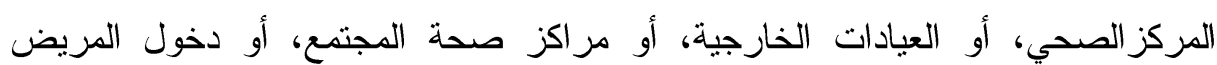

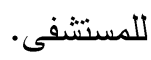
المطومات الصحية: المعلومات التي تهم المريض وكذلك العاملين في المجال الصحي

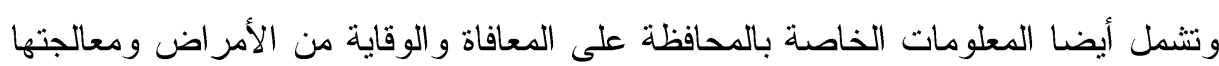

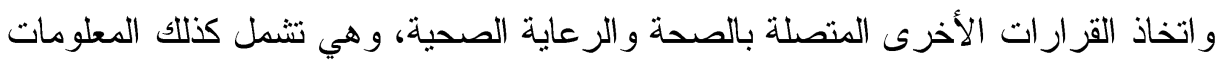
اللازمة لاتخاذ القرارات حول المنتجات الصحية و الخدمات الصحية وهي قد تكون في شكل

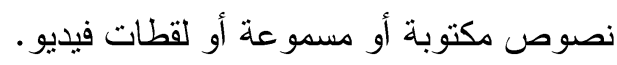

المستثفى: الجزء المتكامل من التنظيم الصحي ووظيفته توفير العناية الصحية الكاملة

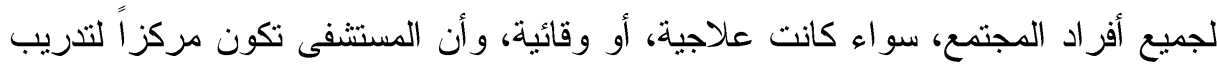

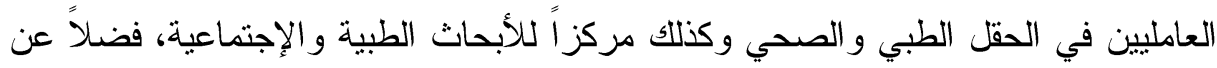

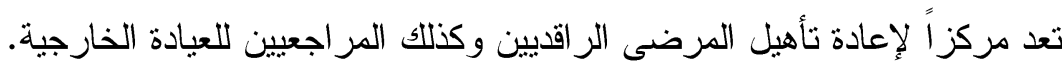

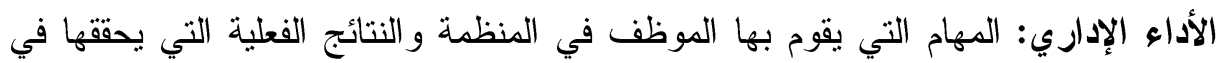

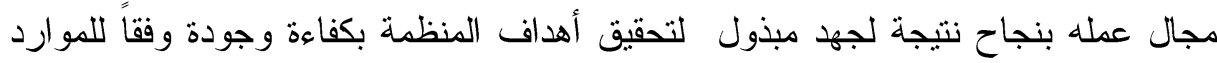

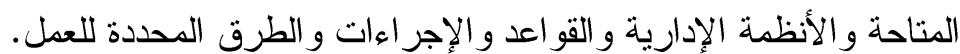


جودة الأداء الإداري: تتفيذ الأعمال المطلوبة بشكل صحيح (بإحسان) من أول مرة دون

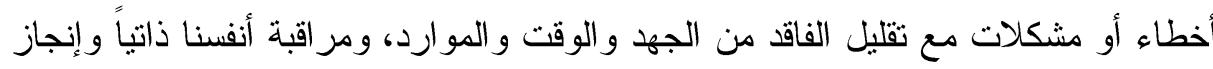

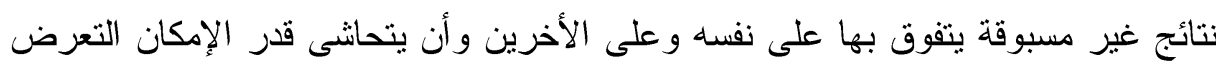
للخطأ.

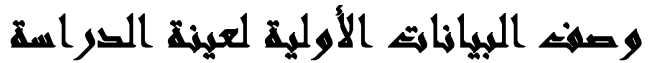

تم جمع البيانات من خلال الاستبيانات التي تم توزيعها واسترجاعها وكانت الصحيحة منها (. 7) استمارة موزعة بين الأقسام محل الدراسة و التي تم من خلآلمها استنتاج البيانات

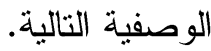

جدول رقم(1): الإحصاء الوصفي لعينة الدراسة البة المية

\begin{tabular}{|c|c|c|c|}
\hline 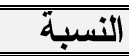 & العدد & المتغير ات المتير & البياتات الوصفية \\
\hline$\overline{\% १ ५ . \mu}$ & $\bar{\Lambda}$ & سنة - أقل من "آسنو ات & \multirow{6}{*}{ عدد سنو ات الخبرة } \\
\hline$\%$ \%४.५ & IV & من بساسنو ات إلى أقل من • اسنو ات & \\
\hline$\%$ \%r.r & T乏 & من • اسنو ات إلى أقل من · بسنة & \\
\hline$\% 10$. & 9 & من • كسنة إلى أقل من •"بسنة & \\
\hline$\%$ \%r... & $\overline{I r}$ & . rاسنة فأكثر & \\
\hline$\% 1 \ldots$ & T. & الإجمالى & \\
\hline$\%$ \%४.ऍ & IV & ما قبل الجامعة & \multirow{5}{*}{ المؤهل العلمي } \\
\hline $7 \% . \mu$ & $r \mu$ & مؤهل جامعى & \\
\hline r.r & r & د د دبلوم دراسات عليا & \\
\hline 0 & $r$ & ماجستير & \\
\hline$\% 1 \ldots$ & 7. & الإجمالى & \\
\hline$\Lambda \Lambda . r$ & or & $\gamma$ & \multirow{2}{*}{ هل لديك درجة إدارية إنشر افية } \\
\hline $11 . \mathrm{V}$ & $\mathrm{v}$ & نعر & \\
\hline$\Lambda \Lambda . \mu$ & or & ليبس لديهم درجة إدارية إنثر افية & \multirow{5}{*}{ الدرجة الإدارية إثر افية } \\
\hline$\% 1 . v$ & 1 & رئيس قسم & \\
\hline$\% \wedge . \varepsilon$ & 0 & 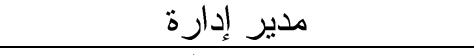 & \\
\hline$\% 1 . \vee$ & 1 & مدير عام - مام مام & \\
\hline$\% 1 \ldots$ & 7. & الإجمالى & \\
\hline
\end{tabular}




\section{يتضح من الجدول السابق ما يلي:}

• غالبية عينة الدراسة كانت عدد سنوات الخبرة لديهم (من آسنوات إلى أقل

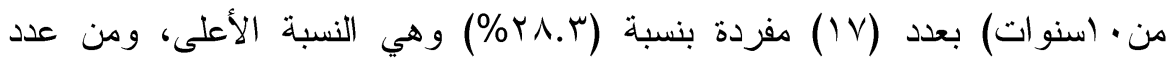

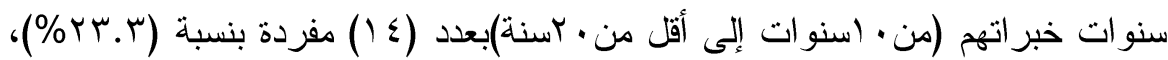

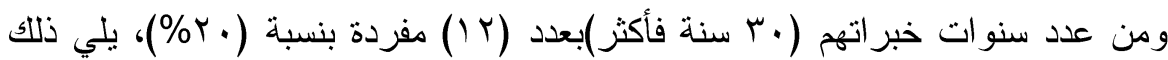

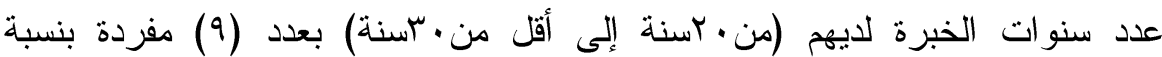

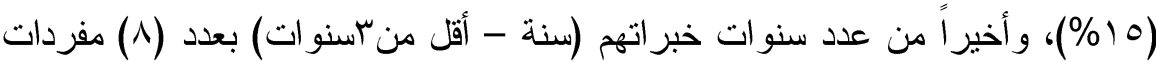

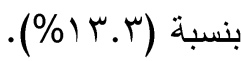

• معظم عينة الدراسة من حملة المؤهل (المؤهل الجامعي) بعدد (به) مفردة بنسبة

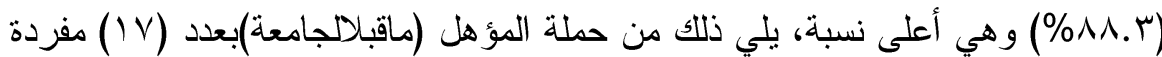

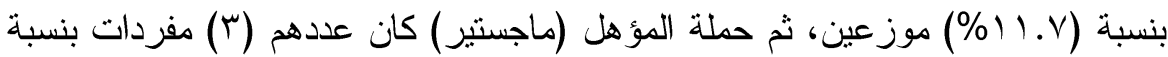

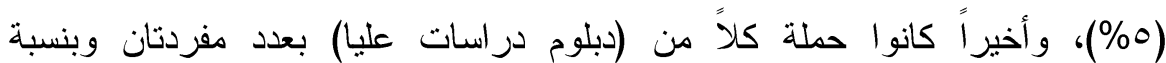

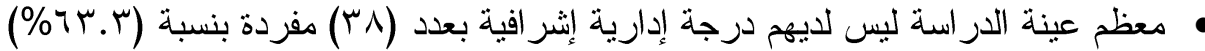

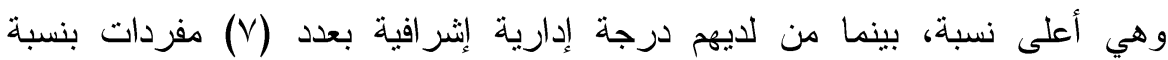

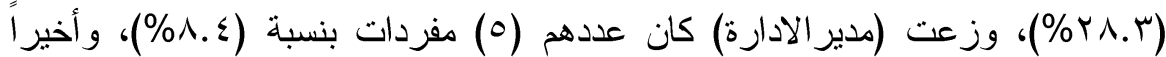
كان كلاً من (رئيس قسم ومدير عام) بعدد مفردة وبنسبة (v) (1\%). جدول رقم(ץ): يوضح توزيع استبيانات الدراسة

\begin{tabular}{|c|c|c|c|c|}
\hline نسبة الاستثميار ات & الاستثمار اتة & الاستتمار ات & عد الاستتمارِ ات & الاقَسام \\
\hline$\% \mathrm{~V}$ & V & $\wedge$ & 1 & شُون العاملين \\
\hline$\% \vee$ & V & V & 1 . & الصيدلية .. \\
\hline$\% 9$. & 9 & 1. & 1 . & الحسابات \\
\hline$\%$ & 11 & Ir & 10 & شئون الأطباء \\
\hline$\% \wedge$ & $\Lambda$ & 9 & $1 \cdot$ & الشطب \\
\hline$\% 77 . \mathrm{V}$ & 1. & 11 & 10 & عيادة الحو امل \\
\hline$\% \wedge$ & $\Lambda$ & $\Lambda$ & 1. & قالتشخ التخصية الأشعة \\
\hline$\% \vee 0$ & 7. & 70 & $\Lambda$. & \\
\hline
\end{tabular}

$$
\text { المجلد الثاني و الثثلاثون، يونيو } 17 \text { ب ا }
$$




\section{أساة الىر اسة}

من أجل تحقيق أهداف الدراسة قام الباحثون بتقسيم الإستبانة إلى قسمين رئيسيين هما: القسم الأول:وهو عبارة عن السمات الثخصية عن المستجيب (سنوات الخبرة، المؤهل العلمى،الدرجة الإنشر افية) القسم الثاني:و هو عبارة عن محاور الدراسة وتتكون الاستبانة من فقرة موزعة على

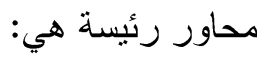
المحور الأول:الإمكانات البشرية تنكون من( • (1) فقرات. المحور الثاني:الإمكانات المادية تتكون من (1) (1) فقرات الإنات المحور الثالث:الإمكانات التنظيمية تتكون من(9) فقرات الإنات

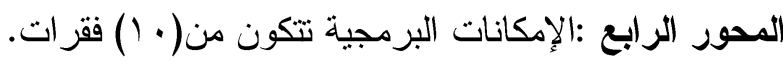

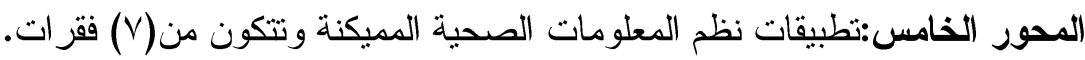

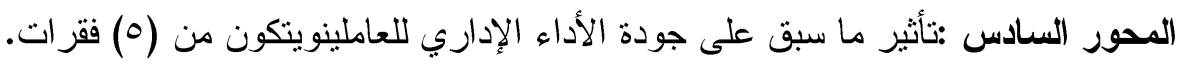

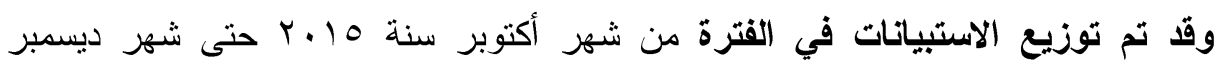
.+10

\section{نمتائج المبثش وهناهشتحها}

إثبات فروض الار اسة: القرض الرئيسي: لا توجد علاقة معنوية بين تطبيق نظم المعلومات البيئية الصحية الميكنة

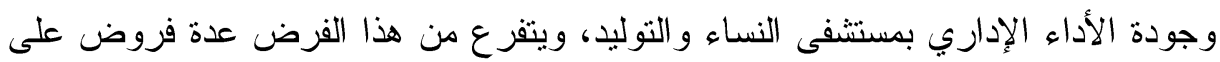

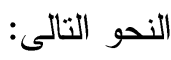
الفرض الأول: لا توجد علاقة معنوية بين توافر الإمكانات البشرية المتاحة لاستخدامنظم المعلومات الصحية المميكنة وجودة الأداء الإداري. 
جلول رقم (ץ): اختبار الإنحدار البسيط لتأثير توافر الإمكانات البشرية المتاحة لاستخدام

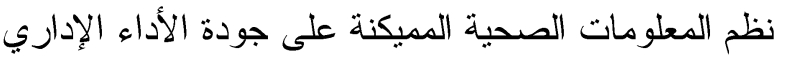

\begin{tabular}{|c|c|c|c|c|c|c|}
\hline المعنوية & $\begin{array}{l}\text { قيمةت } \\
\text { (t) }\end{array}$ & قيمة ف & $\begin{array}{l}\text { التحامي } \\
\text { (R2) }\end{array}$ & $\begin{array}{l}\text { الإرتبامط } \\
\text { (R) }\end{array}$ & $\begin{array}{c}\text { الإحدار(B) } \\
\text { (B) }\end{array}$ & المتغيرات المستقلة \\
\hline 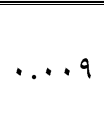 & r.V10 & V.rVT &. .114 & דצr. & .rYo- & 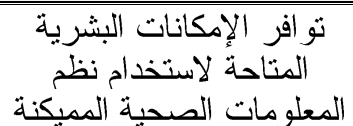 \\
\hline
\end{tabular}

لاراسة نطبيق نظم المعلومات الصحية المميكنة وأثزه على جودة الأداء الإداري

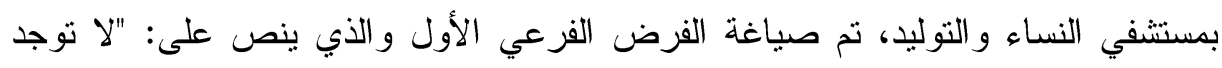

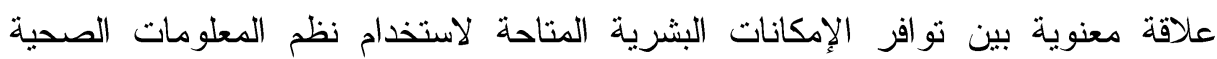
المميكنة وجودة الأداء الإداري".

يتضح من نتائج تحليل الانحدار الخطي البسيط في الجدول السابق أن قيمة معامل

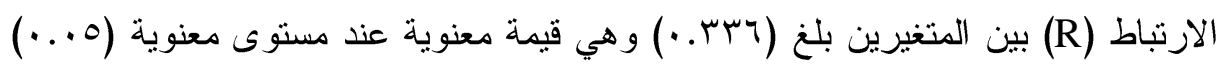

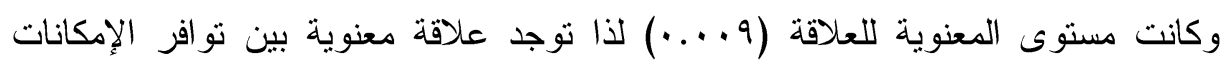
البشرية المتاحة لاستخدام نظم المعلومات الصحية الميكنة وجودة الأداء الإداري.

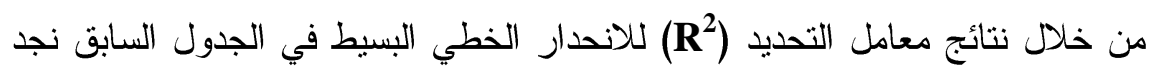

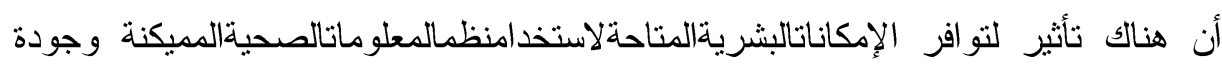

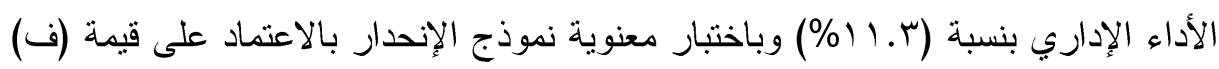

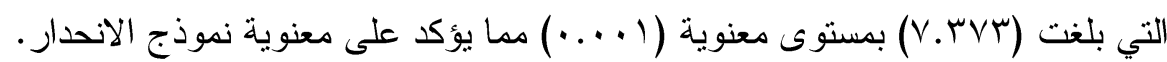

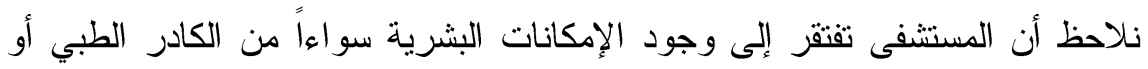
الإدارى المدرب على إستخدام نظم المعلومات ومن واقع ملاحظة الباحثة وجدت أنى أن نسبة الإنة العاملين المُحالين إلى المعاش خلال الخمس سنو ات القادمة النسبة الأكبر من حجم العاملين بمستثفى النساء والتوليد وفى المقابل ندرة العاملين الجدد ومع نقص الإمكانات المادية و التكنولوجية و التتظيمية داخل المستشفى فلابد أن ينتبه المسئولين عن إدارة مستتفى النساء و التوليد عن تلك الأزمة ومحاصرتها قبل أن تتفاقم. 
تم من خلال النموذج اختبار معنوية معامل الانحدار (B) و الذي يوضح وجود معنوية بين تو افر الإمكانات البشرية المتاحة لاستخدام نظم المعلومات الصحية المميكنة وجودة الصناء

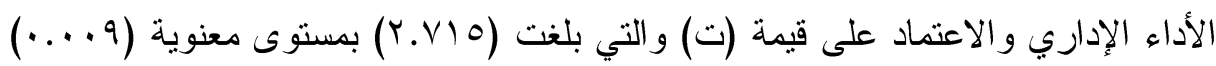

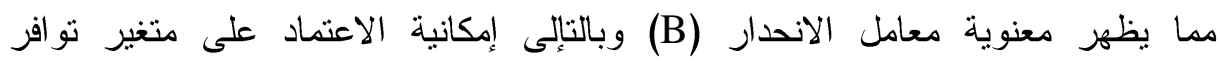

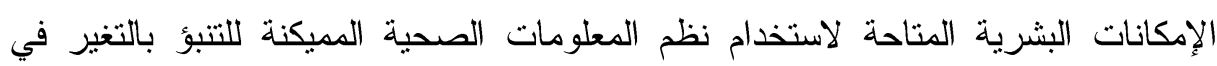
تحسين جودة الأداء الإداري.

لذا نرفض الفرض البديل الذب ينص على أنه لا توجد علاقة معنوية بين نوافر الإمكانات البشرية المتاحة لاستخدام نظم المعلومات الصحية المميكنة وجودة الأداء

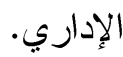

ونقبل الفرض العدمي بأنه نوجد علاقة معنوية بين نوافر الإمكانات البشرية المتاحة لاستخدام نظم المعلومات الصحية المميكنة وجودة الأداء الإداري. الفرض الفرعي الثاني: لا توجد علاقة معنوية بين توافر الإمكانات المادية المتاحة

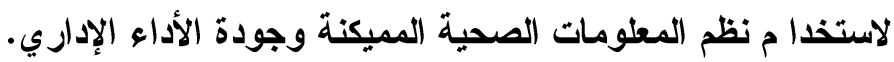
جدول رقم(ع): اختبار الإنحدار البسيط لتأثير تو افر الإمكانات المادية المتاحة لاستخدام نظم المعلومات الصحية المميكنة على جودة الأداء الإداري الإني

\begin{tabular}{|c|c|c|c|c|c|c|}
\hline مستوية & $\begin{array}{c}\text { قيمة } \\
\text { (t) }\end{array}$ & 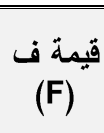 & $\begin{array}{l}\text { معامل } \\
\text { (R2) } \\
\text { (R2) }\end{array}$ & $\begin{array}{l}\text { الإرتباط } \\
\text { (R) } \\
\text { (R) }\end{array}$ & $\begin{array}{c}\text { الإحدار(B) } \\
\text { (B) }\end{array}$ & المتغيرات المستقلة \\
\hline$\ldots r$ & $r . . \leqslant \wedge$ & Q.Y Y &. $.1 r \wedge$ & . IVY & $\cdot r \leqslant 0-$ & تلاستخدام نظم الإمكانات المعلومات المتاحة \\
\hline
\end{tabular}

لدراسة نطبيق نظم المعلومات الصحية المميكنة وأثره على جودة الأداء الإداري بمستشفي النساء والتوليد، نم صياغة الفرض الفرعي الثاني و الذي ينص على: "لا توجد الته

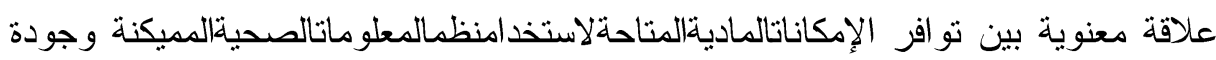
الأداء الإداري". 
يتضح من نتائج تحليل الانحدار الخطي البسيط في الجدول السابق أن قيمة معامل

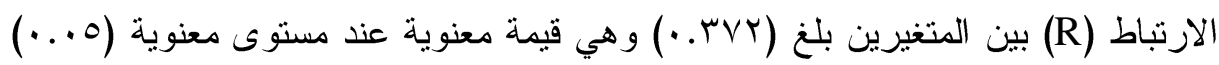

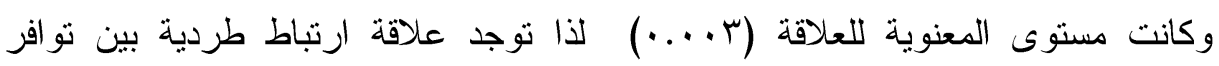

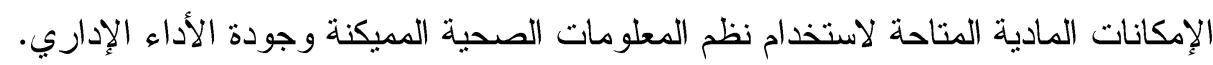
من خلال نتائج معامل التحديد (R) للانحدار الخطي البسيط في الجدول السابق نجد

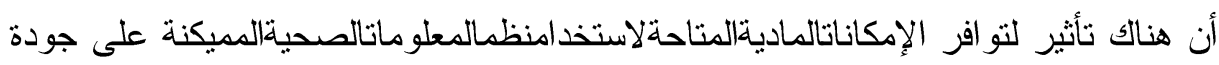

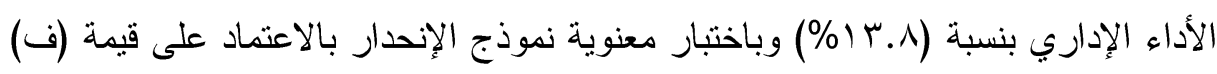

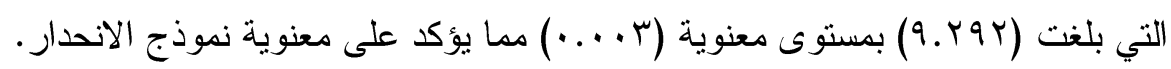

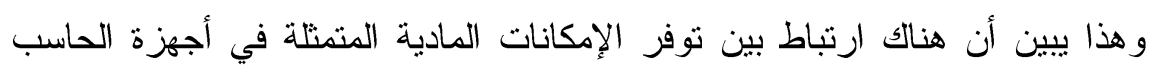

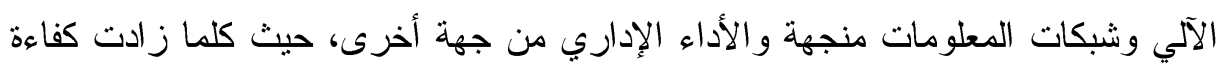

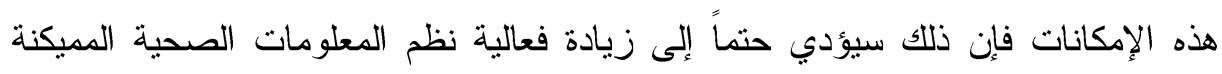

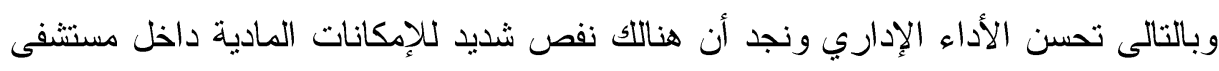
النساء و التوليد.

تم من خلال النموذج اختبار معنوية معامل الانحدار (B) و الذي يوضح وجود علاقة طردية بين نوافر الإمكانات المادية المتاحة لاستخدام نظم المعلومات الصحية المميكنة

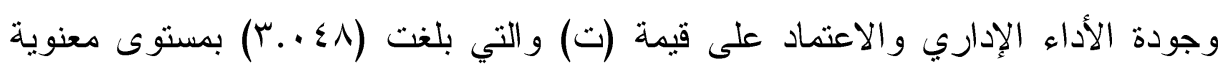

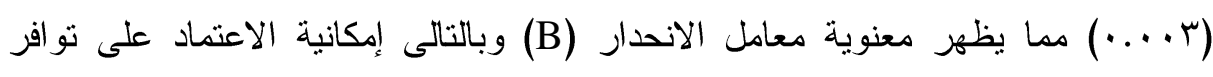

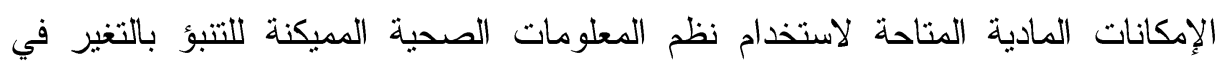
تحسين جودة الأداء الإداري. لذا نرفض الفرض البديل الذي ينص على أنه لا نوجد علاقة معنوية بين توافر الإدر

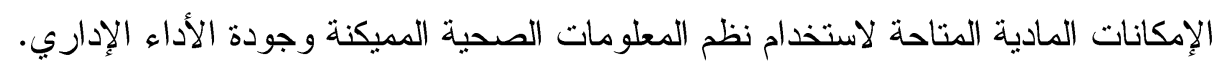
ونقبل الفرض العدمي بأنه توجد علاقة معنوية بين توافر الإمكانات المادية المتاحة لاستخدام نظم المعلومات الصحية المميكنة وجودة الأداء الإداري. 
الفرض الفرعي الثالث: لا توجد علاقة معنوية بين توافر الإمكانات التنظيمية المتاحة لاستخدام نظم المعلومات الصحية الميكنة وجودة الأداء الإداري.

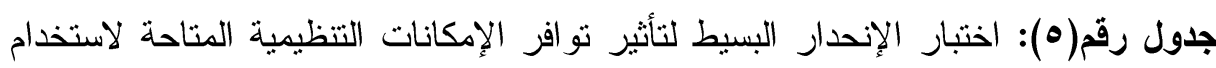

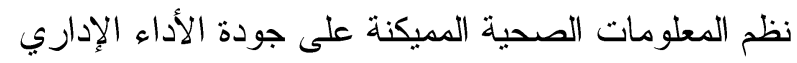

\begin{tabular}{|c|c|c|c|c|c|c|}
\hline المعنوية & قيمة ت & فت (F) & $\begin{aligned} \text { (التحداميد } \\
\left(\mathbf{R}^{2}\right)\end{aligned}$ & $\begin{array}{l}\text { الإزتباط } \\
\text { (R) }\end{array}$ & الإحدار (B) & المتغيرات المستقلة \\
\hline ....r & r.TVV & $9 . .71$ & $.1 \leqslant 0$ & $\theta r \leqslant r$ & . Y07- & 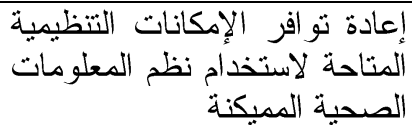 \\
\hline
\end{tabular}

لدراسة تطبيق نظم المعلومات الصحية المميكنة وأثره على جودة الأداء الإداري

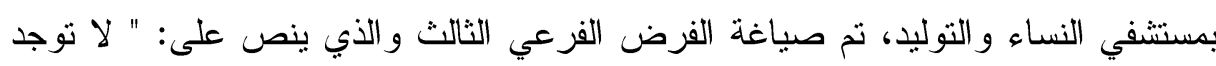
علاقة معنوية بين توافر الإمكانات التنظيمية المتاحة لاستخدام نظم المعلومات الصحية

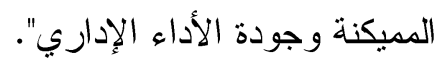

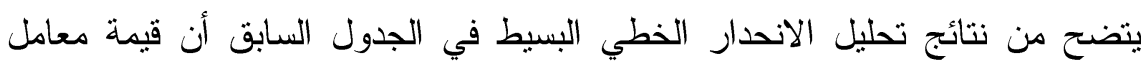

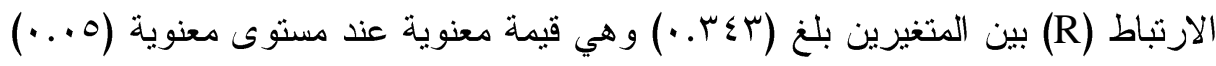

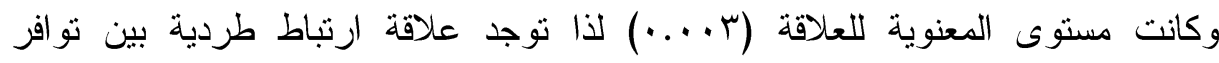

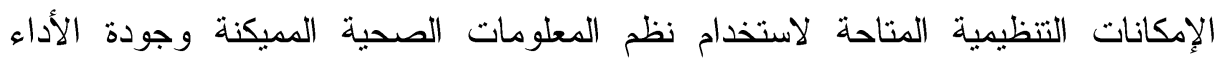

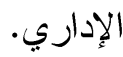

من خلال نتائج معامل التحديد (R2) للانحدار الخطي البسيط في الجدول السابق نجد

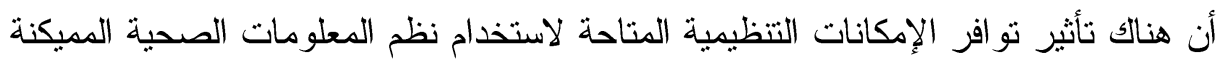

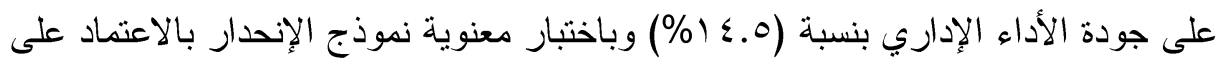

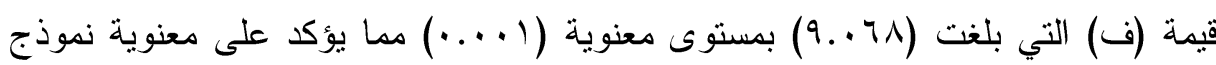
الانحدار.

وترجع هذه النسبة إلى عدم تو افر الإمكانات التنظيمية داخل المستثفى 
تم من خلال النموذج اختبار معنوية معامل الانحدار (B) و الذي يوضح وجود علاقة طردية بين إعادة هندسة عمليات الخدمات المصرفية ومؤشر السيولة بالبنوك التجارية

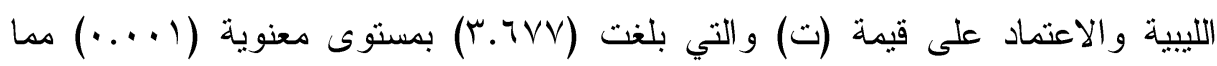
يظهر معنوية معامل الانحدار (B) وبالتإلى إمكانية الاعتماد على متغير تو افر الإمكانات

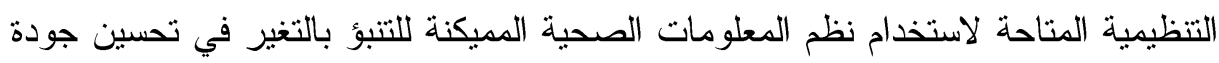

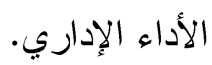

لذا نرفض الفرض البديل الذي ينص على أنه لا توجد علاقة معنوية بين تو افر الفران

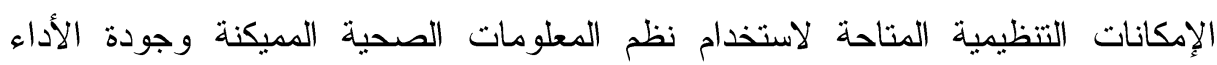
الإداري.

ونقبل الفرض العدمي بأنه توجد علاقة معنوية بين توافر الإمكانات التتظيمية المتاحة

لاستخدام نظم المعلومات الصحية المميكنة وجودة الأداء الإداري.

الفرض الفرعي الرابع: لا توجل علاقة معنوية بين تواقر الإكانات البرمجية المتاحة

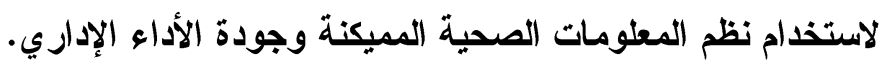

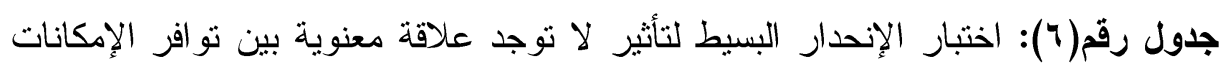

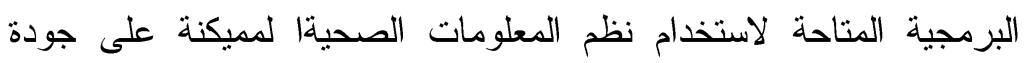

الأداء الإداري - معايه

\begin{tabular}{|c|c|c|c|c|c|c|}
\hline المعنوية & 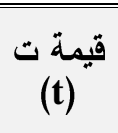 & قيمة ف & $\begin{array}{l}\text { التحاملد } \\
\text { (Rعل } \\
\left(\mathbf{R}^{2}\right)\end{array}$ & $\begin{array}{c}\text { الإرتباط } \\
\text { معامل } \\
\text { (R) }\end{array}$ & الإحدارد & المتغيرات المستقلة \\
\hline$\ldots 1$ & r.0YT & $T . \leqslant \mu \leqslant$ & $\cdot 1 \ldots$ & . & 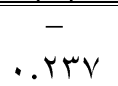 & تو افر الإمكانات البرمجية \\
\hline
\end{tabular}

لدراسة نطبيق نظم المعلومات الصحية المميكنة وأثره على جودة الأداء الإداري

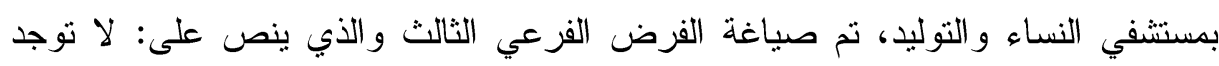
علاقة معنوية بين توافر الإمكانات البرمجية المتاحة لاستخدام نظم المعلومات الصحية

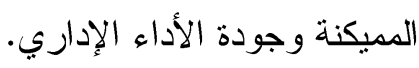


يتضح من نتائج تحليل الانحدار الخطي البسيط في الجدول السابق أن قيمة معامل

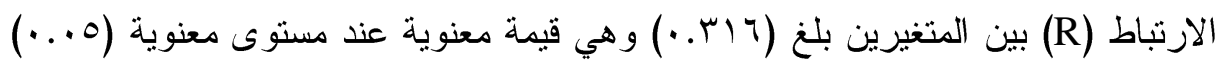
وكانت مستوى المعنوية للعلاقة (1 ...) لذا توجد علاقة ارتباط طردية بين تو افر الإمكانات البرمجية المتاحة لاستخدام نظم المعلومات الصحية المميكنة وجودة الأداء الإداري. من خلال نتائج معامل التحديد (R2) للانحدار الخطي البسيط في الجدول السابق نجد أن هناك تأثير لتو افر الإمكانات البرمجية المتاحة لاستخدام نظم المعلومات الصحية المميكنة

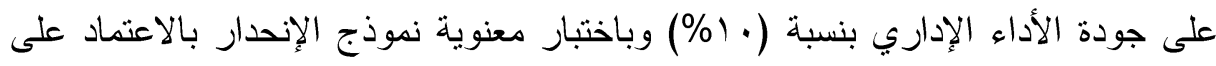

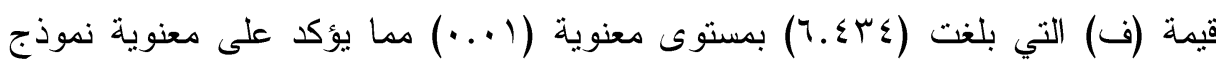
الانحدار .

ونلاحظ أن نقص الإمكانات البرمجية يؤثرعلى كفاءة الأداء بالمستثفى ومن خلا

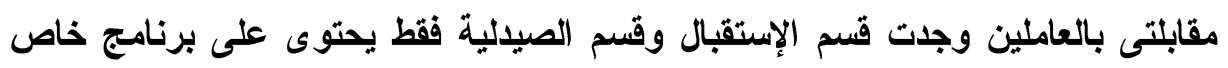
بكل قسم ولا يوجل برنامج متكامل لنظم المعلومات الصحية على مستوى المستشفى ككل.

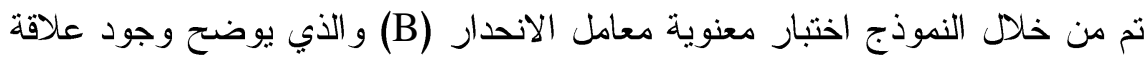
طردية بين تو افر الإمكانات البرمجية المتاحة لاستخدام نظم المعلومات الصحية المميكنة

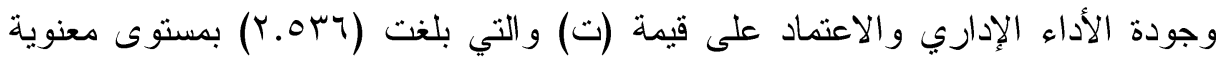

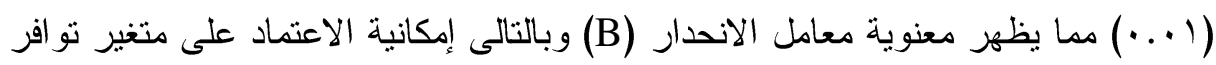

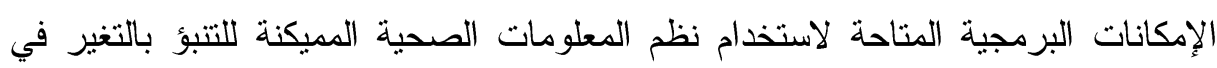
تحسين جودة الأداء الإداري. لذا نرفض الفرض البديل الذي ينص على أنه لا توجد علاقة معنوية بين توافر

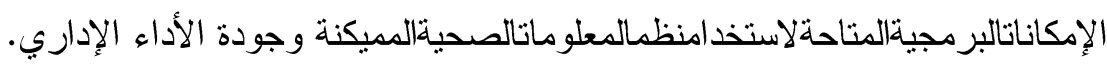
نقبل الفرض العدمي بأنه توجد علاقة معنوية بين توافر الإمكانات البرمجية المتاحة

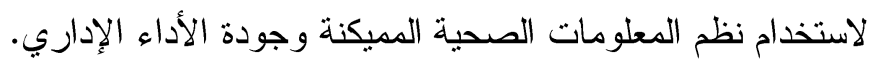


الفرض الرئيسي: لا توجد علاقة معنوية بين تطبيق نظم المعلومات البيئية الصحية الميكنة وجودة الأداء الإداري بمستشفى النساء و التوليد. جدول رقم(V): اختبار الإنحدار المتعدد لتأثبر تطبيق نظم المعلومات البيئية الصحية المميكنة على جودة الأداء الإداري

\begin{tabular}{|c|c|c|c|c|c|c|c|}
\hline $\begin{array}{l}\text { التصائ } \\
\text { (R2) }\end{array}$ & $\begin{array}{c}\text { الإرتباط } \\
\text { (R) } \\
\text { (R) }\end{array}$ & المعنوية & فيمة & المعنوية & تقيمة & $\begin{array}{l}\text { الإنحدار } \\
\text { (B) } \\
\text { (B) }\end{array}$ & المتغير ات المستقلة \\
\hline \multirow[b]{5}{*}{$\cdot r \cdot T$} & \multirow[b]{5}{*}{$. r \leqslant q$} & \multirow[b]{5}{*}{..$r$} & \multirow[b]{5}{*}{ r.A.. } &.$\pi$ &. .91 . & $. .111-$ & الإمكاناتالبشرية \\
\hline & & & & $\cdots \cdots$ & Y.VAV & . Yor- & الإمكانياتالمادية \\
\hline & & & & $\ldots V$ & $1 . \wedge \Lambda \mathrm{V}$ & . & الإمكاناتالتنظيمية \\
\hline & & & &.$r \mathrm{r}$ & $1 . \mathrm{rov}$ &. TYV & الإمكاناتالبرمجية \\
\hline & & & &. $.9 \mathrm{~V}$ & $\ldots r$. & $\ldots .7$ & 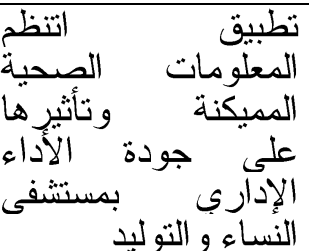 \\
\hline
\end{tabular}

لار اسة تطبيق أثز نظم المعلومات البيئية|الصحية المميكنة على جودة الأداء الإداري بمستثفي النساء والتوليد، تم صياغة الفرض الرئيسي: لا توجد علاقة معنوية بين تطبيق

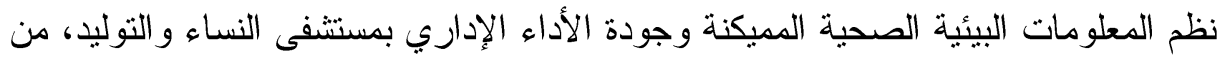
خلال اختبار تحليل الانحدار المتعدد في الجدول السابق أن قيمة معامل الارنباط (R) بين

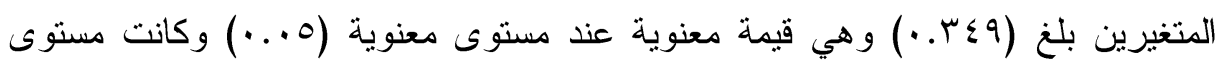
المعنوية للعلاقة (س ...) لذا توجد علاقة ارتباط طردية بين تطبيق نظم المعلومات البيئية الصحية المميكنة وجودة الأداء الإداري.

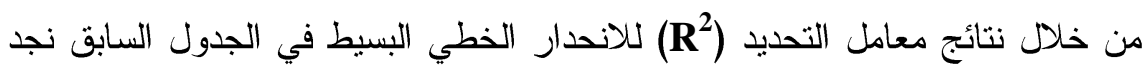
أن هناك تأثير تطبيق نظم المعلومات البيئية الصحية المميكنة على جودة الأداء الإداري بنسبة (T. • †\%) وباختبار معنوية نموذج الإنحدار بالاعتماد على قيمة (ف) التي بلغت (Y.A.) 
تشير نتائج إجابات أفراد العينة نحو موافق ومواقق جداً إذا تم تطبيق نظم المعلومات الصحية المميكنة على مستوى المستشفى ككل، ويؤدى ذلتك إلى رفع جودة

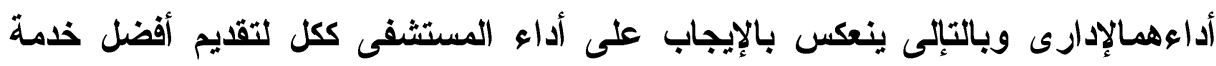
للمرضى.

لذا نرفض الفرض البديل الذي ينص على أنه الفرض الرئيسي: لا توجد علاقة معنوية

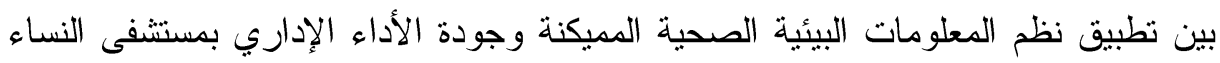
و التوليد.

نقبل الفرض العدمي بأنه الفرض الرئيسي: توجد علاقة معنوية بين تطبيق نظم المعلومات البيئية الصحية المميكنة وجودة الأداء الإداري بمسنشفى النساء و التوليد. توانه

\section{نتمائج المبحثي}

1-يتضح من نتائج الدراسة أن قيمة معامل الارتباط (R) بين نو افر الإمكانات البشرية

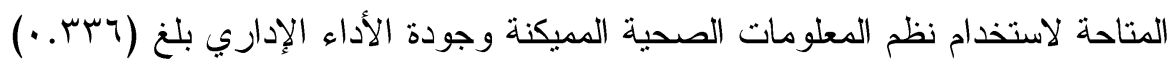
و هي قيمة معنوية عند مستوى معنوية (0...) وكانت مستوى المعنوية للعلاقة (9 . . . لذا توجد علاقة معنوية بين نو افر الإمكانات البشرية المتاحة لاستخدام نظم المعلومات الصحية المميكنة وجودة الأداء الإداري. r-يتضح من نتائج الدراسة أن قيمة معامل الارتباط (R) بين تو افر الإمكانات المادية

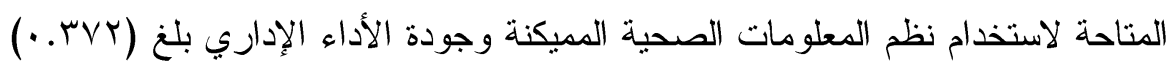
و هي قيمة معنوية عند مستوى معنوية (0...) وكانت مستوى المعنوية للعلاقة

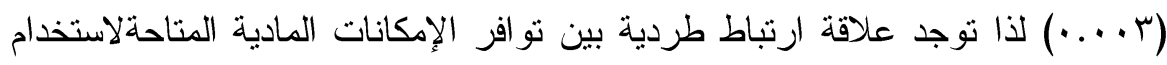

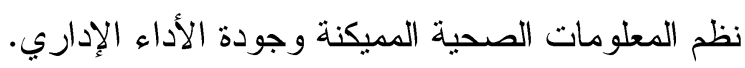
ب-يتضح من نتائج الدراسة أن قيمة معامل الارتباط (R) بين توافر الإمكانات التنظيمية

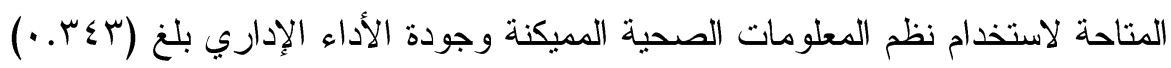
و هي قيمة معنوية عند مستوى معنوية (0...) وكانت مستوى المعنوية للعلاقة 


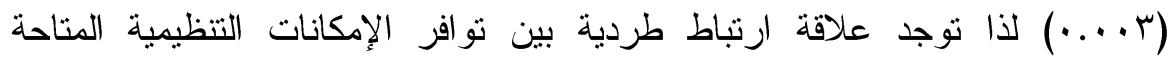
لاستخدام نظم المعلومات الصحية المميكنة وجودة الأداء الإداري.

ع-يتضح من نتائج الدراسة أن قيمة معامل الارتباط (R) بين توافر الإمكاندات الإدات البرمجية

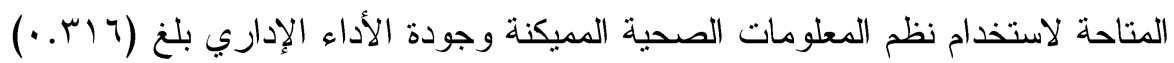

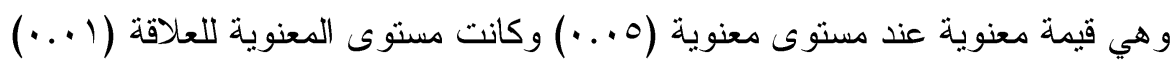
لذا توجد علاقة ارتباط طردية بين توافر الإمكانات البرمجية المتاحة لاستخدام نظم المعلومات الصحية المميكنة وجودة الأداء الإداري.

ه-من خلال نتائج الدراسة أن قيمة معامل الارتباط (R) بين تطبيق نظم المعلومات البيئية

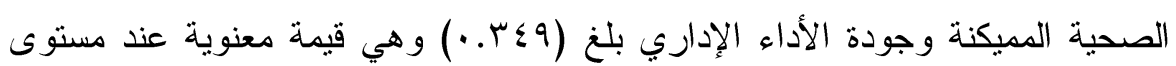

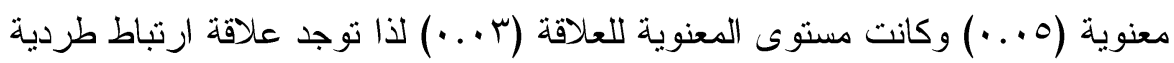
بين تطبيق نظم المعلومات البيئية الصحية المميكنة وجودة الأداء الإداري.

\section{تموسياءث المبحث}

1-توفير أجهزة كمبيوتز لجميع الأقسام داخل مستشفى النساء والتوليد التيت عاني من نقص أو عدم تو افر هذه الأجهزة وبأعداد ومو اصفات جيدة. r- إنشاء نظام معلومات صحى متكامل على كافة الأقسام والإدارات داخل مستثفى النساء و التوليد.

ب-التخلص من الملف الصحي الورقي تدريجيا والبدء بتنفيذ نظام السجل الصحي الالكتروني داخل مستثفى النساء و التوليد.

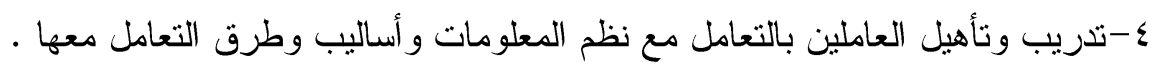

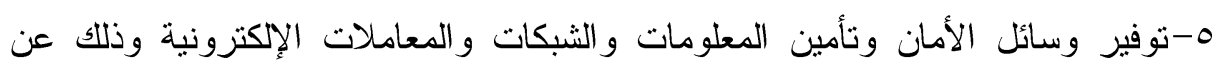
طريق تشفير البيانات، بالإضافة إلى توعية المستشفيات بتوفير المعلومات الكاملة

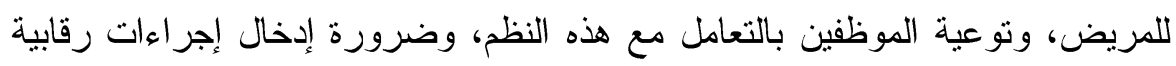


على الأجهزة المستخدمة في المستشفى تحول دون تعرض أمن وسرية المعلومات

$$
\text { للضرر. }
$$

1-ضرورة التعاون مع الجهات الحكومية على تنظيم البنية التشريعية والتنظيمية بحيث

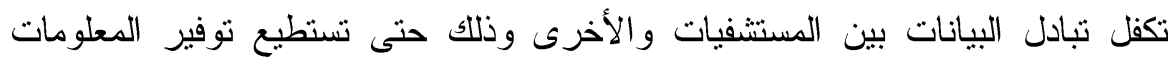
الكاملة للمرضى داخل المستشفى. تبادي. V-توفير بريد الكتروني خاص لكل موظف مما يسهل عملية تبادل المعلومات بين الموظفين ويزيد من التو اصل مع الإدارة العليا فيما يخص آخر المستجدات.

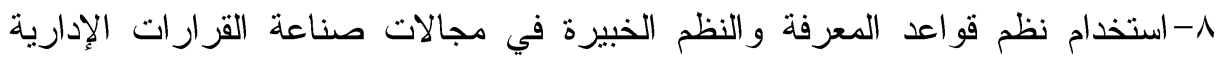
و الطبية في المستشفى لما لها من أثر فيرفع فعالية القرار ات من خلال تحسين نوعيتها،

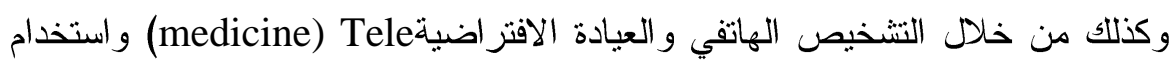
الصحة عن بعد على الانترنت.

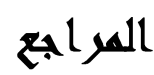

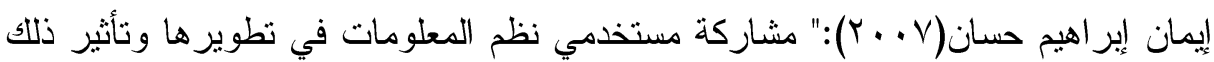

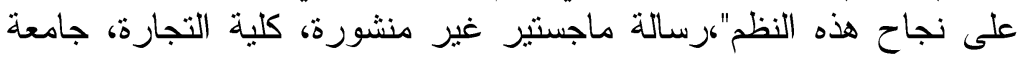

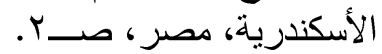

على عبد الوهاب وعايدة سيد خطاب(سو99 (1): " إدارة الأفراد و العلاقات الإنسانية"، المكتبة

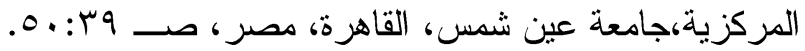

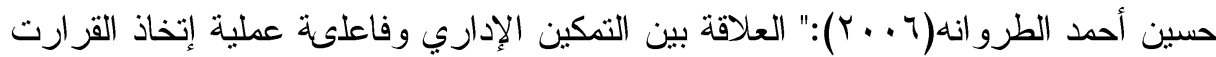

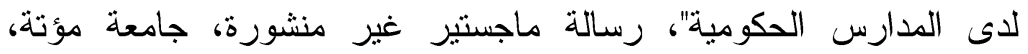

$$
\text { الأردن. }
$$

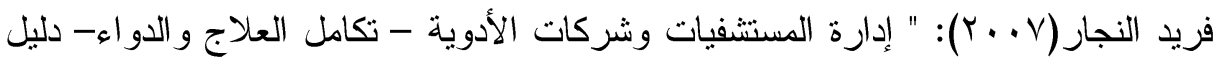

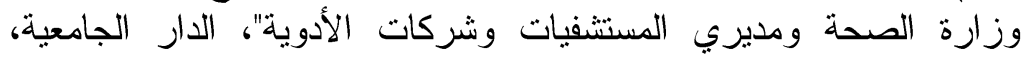

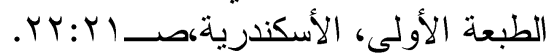


طارق عبد العال حماد وآخرون

محمد عزات عبد العزيز درويش(•(ب):"تأثير تطبيق نظم المعلومات على جودة العملية

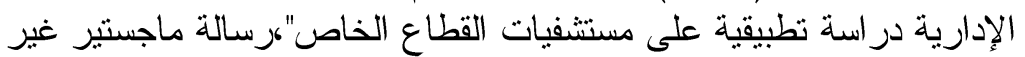

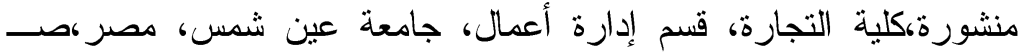

$.1 \leqslant Y: 1 T 9$ 6rV

Schoen, C., Osborn, R., Squires, D., Doty, M., Rasmussen, P., Pierson, R. and Applebaum, S(2012):

"A Survey Of Primary Care Doctors In Ten Countries Shows Progress In Use Of Health Information Technology, Less In Other Areas", Health Affairs Web First, published online Nov. 15, 2012 ,

http://content.healthaffairs.org/content/31/12/2805.full.html, 2012. 
مجلة العلوم البيئية

معهد الدراسات و البحوث البيئية - جامعة عين شمس لئس

\title{
FRAMEWORK FOR APPLICATION OF ENVIRONMENT INFORMATION SYSTEMS AND \\ IMPACT TO THE QUALITY OF ADMINISTRATIVE \\ PERFORMANCE AIN SHAMS UNIVERSITY \\ HOSPITAL
}

\author{
Hammad, T. A. ${ }^{(1)}$; Al- Bukhari, M. S. ${ }^{(2)}$; Ramadan, Somiah, M. ${ }^{(1)}$ \\ and Alazab, Mona, M. ${ }^{(3)}$ \\ 1) Faculty of Commerce, Ain Shams University 2) Institute of \\ Environmental Studies \& Research, Ain Shams University 3) Faculty of \\ Medicine, Ain Shams University
}

\begin{abstract}
The current research purpose is to identify the actual reality of using the mechanic health information systems in Women and Giving Birth Hospital of Ain Shams University, identifying as well the quality of the management system of its personnel in addition to those employees' perception of towards the available (materialisticprogrammatic-human-organizational) potentialities for using mechanic health informative systems.

This study also discusses the concept of the mechanic health informative systems and the concept of the quality of the management system.

The study hypothesizes a correlation exists between application of the mechanic health information systems in Women and Giving Birth Hospital of Ain Shams University, the mechanic health information systems in Women and Giving Birth Hospital of Ain Shams University and quality of the management system.

The study uses the descriptive (qualitative) analytical method for forming the research theoretical framework. Data are collected through 514

$$
\text { المجلد الثاني و الثلاثثون، يونيو } 17
$$
\end{abstract}


طارق عبد العال حماد وآخرون

an investigation form as the research main tool. The sample consists of (80) employees in Women and Giving Birth Hospital of Ain Shams University. Results indicate a significant statistical relationship exists between the mechanic health information systems and the administrative performance of the employees of the hospital at significance level (0.01).

The study recommends establishing a specialized technical division involved in mechanic health information, holding training courses also in field of using the health informatics, and considering and caring as well of providing a perfect modern networks for quicker communication.

$$
\text { المجلد الثاني و الثناثثون، يونيو } 17 \text { ـ }
$$

